\title{
AOD Trends over Megacities Based on Space Monitoring Using MODIS and MISR
}

\author{
Pinhas Alpert, Olga Shvainshtein, Pavel Kishcha \\ Department of Geophysical, Atmospheric and Planetary Sciences, Tel Aviv University, Tel Aviv, Israel \\ Email: pavelk@post.tau.ac.il
}

Received June 21, 2012; revised July 20, 2012; accepted July 30, 2012

\begin{abstract}
Space monitoring of aerosol optical depth (AOD) trends over megacities can serve as a potential space indicator of global anthropogenic air-pollution changes. Three space aerosol sensors, MODIS-Terra, MODIS-Aqua and MISR, were used in order to study recent decadal trends of AOD over megacities around the world. Space monitoring of AOD trends has the advantage of global coverage and applies the same approach to detecting AOD trends over different sites. In spite of instrumental and time differences among the three sensors investigated, their global pictures of AOD trends over the 189 largest cities in the world are quite similar. The increasing AOD trends over the largest cities in the Indian subcontinent, the Middle East, and North China can be clearly seen. By contrast, megacities in Europe, the northeast of US, and South-East Asia show mainly declining AOD trends. In the cases where all three sensors show similar signs of AOD trends, the results can be considered as reliable. This is supported by the observed trends in surface solar radiation, obtained by using network pyranometer measurements in North and South China, India, and Europe. In the cases where the three sensors show differing signs of AOD trends (e.g. South America), additional research is required in order to verify the obtained AOD trends.
\end{abstract}

Keywords: Megacities; Aerosols; Aerosol Optical Depth; Space Monitoring; Air-Pollution

\section{Introduction}

In megacities, which are defined as metropolitan areas with population exceeding 10 million inhabitants, air quality is worsening as the population, traffic, industrialization and energy use are increasing [1,2]. Evaluating air pollution over megacities is crucial, because of pollution transport between different parts of the world. Aircraft and satellite data reveal that, within a week, emissions can be transported half way around the world into trans-oceanic and trans-continental plumes, no matter whether they are from Asia, North America, or Africa [3]. Therefore, emissions and ambient concentrations of pollutants in megacities can have widespread effects. Anthropogenic emissions can impact health; visibility; regional ecosystems; regional climate change; and global pollutant transport, as discussed in many studies, e.g. [1, 4-7]. The London smog of 1952 is one of history's most important air pollution episodes in terms of its impact on public perception of air pollution and subsequent government regulation [4]. Decker et al. [5] claimed that rapid population growth in megacities in developing countries is accompanied by significant contamination of urban territories, as well as air and water pollution.

Because of increasing anthropogenic pollution, changes in atmospheric aerosol concentration over megacities can cause radiative forcing of the climate (known as the aerosol direct effect) and modify cloud properties (known as the aerosol indirect effect) [8-10]. Solar dimming is a widespread decrease in surface solar radiation by several percents $[11,12]$ and is considered to be a consequence of increasing anthropogenic pollution. Using the Global Energy Balance Archive (GEBA) of pyranometer network data, Alpert et al. [13] showed that, during the period 1964-1989, solar dimming was stronger over large urban sites than over sparsely-populated sites. Alpert and Kishcha [14] found that, in general, the average surface solar radiation flux, based on worldwide pyranometer measurements, decreases with population density as a monotonic function. Furthermore, Kishcha et al. [15] showed that, over extensive areas with differing population densities in the Indian subcontinent, the higher the averaged population density - the larger the averaged AOD. In addition, the larger the population growth is, the stronger the increasing AOD trends are observed.

Unlike ground-based measurements, satellite remote sensing of aerosols has the advantage of providing global coverage on a regular basis [10]. This provides us with an opportunity to compare aerosol tendencies in different megacities using satellite data of the same sensors. The 
current study was aimed at estimating aerosol optical depth (AOD) trends over the largest cities in the world in relation with the aerosol emission changes during the period 2002-2010. In the current study, global distribution of AOD tendencies over the largest cities in the world was verified by comparing the following three sensors: MODIS-Terra, MODIS-Aqua, and MISR. MODISAqua and MODIS-Terra have a wide viewing swath and their cameras are focused straight down on the Earth's surface. MISR is a multi-angle imaging spectro-radiometer; its cameras acquire images with several angles relative to the Earth's surface [16]. The multi-angle views ensure that MISR can provide aerosol optical thickness retrievals in areas where the Sun's glint precludes MODIS from doing so. MISR and MODIS aerosol retrievals successfully complement each other [17]. Therefore, comparisons between aerosol optical depth and its tendencies based on both MODIS and MISR data can help us expand our knowledge about aerosol tendencies over the largest cities in the world.

\section{Data}

Our approach to estimating the effect of urbanization on AOD over the largest cities in the world was based on analyzing long-term variations of AOD. To attain the goal we used AOD data from the three aforementioned aerosol sensors on board the NASA Terra satellite (launched in December 1999) and the NASA Aqua satellite (launched in May 2002). The effect of urbanization on AOD was estimated for the eight-year period from July 2002 to June 2010, when data from the all three sensors were available. Note that, for MODIS-Terra, a comparison between the ten-year AOD trends and the eightyear AOD trends have shown very similar results; therefore, we preferred to study the results for the three sensors during the aforementioned eight-year period.

\subsection{MODIS Data}

The Moderate Resolution Imaging Spectroradiometer (MODIS) is a sensor with the ability to characterize the spatial and temporal characteristics of the global aerosol field. MODIS has 36 channels spanning the spectral range from 0.41 to $15 \mu \mathrm{m}$. MODIS with its $2330 \mathrm{~km}$ viewing swath provides almost daily global coverage. The MODIS AOD uncertainty over the land is $\triangle \mathrm{AOD}= \pm(0.05+15 \%)$ $[18,19]$. Collection 5 (MOD08_M3.050) of MODIS-Terra and collection 5.1 of MODIS-Aqua (MYD08_ M3.051) level-3 monthly aerosol data with global $1^{\circ} \times 1^{\circ}$ grid were used in the current study.

\subsection{MISR Data}

The Multi-angle Imaging SpectroRadiometer (MISR) [16] employs nine discrete cameras pointed at fixed angles, one viewing the nadir (vertically downward, $0^{\circ}$ ) direction and four each viewing the forward and afterward directions $(26.1,45.6,60.0$, and 70.5 degrees). Each camera measures in four different wavelengths: $443 \mathrm{~nm}$ (blue band), $555 \mathrm{~nm}$ (green band), $670 \mathrm{~nm}$ (red band) and $865 \mathrm{~nm}$ (near-infrared). MISR provides global coverage data every 9 days. According to Liu et al. [20] the overall retrieval accuracy of MISR AOD fall within $\triangle \mathrm{AOD}= \pm 0.04 \pm 0.18 \mathrm{AOD}$. It should be mentioned that Liu et al. [20] used older version of the MISR AOD product than we used in the current study. In our study, the MISR monthly level-3 data aerosol product with global grid of $0.5^{\circ} \times 0.5^{\circ}$ was used.

Recently, Oo et al. [21] compared MODIS AOD Level 2 data of $10-\mathrm{km}$ standard resolution with AERONET AOD measurements in New York City. They showed that, for pixels in immediate proximity to the AERONET site, MODIS AOD overestimated AERONET AOD, while MODIS AOD, averaged over a $80 \mathrm{~km} \times 80 \mathrm{~km}$ area centered at the AERONET site and included both urban and vegetation surface types, much better corresponded to AERONET AOD [21]. In the current study, we used $1^{\circ} \times 1^{\circ}$ MODIS and $0.5^{\circ} \times 0.5^{\circ}$ MISR gridded monthly data of AOD. This could minimize some existing problems of the underestimation of surface reflection over urban areas by MODIS and MISR.

\subsection{Cloudiness Effects}

MODIS and MISR have quite a limited opportunity to view aerosols if cloud cover is higher than 0.8 [22-26]. It means that satellite aerosol retrievals obtained under such overcast conditions are less accurate than AOD obtained when cloud presence is rather low. Moreover, in accordance with Remer et al. [26] and Zhang et al. [23], it is possible that, when cloud fraction exceeds 0.8 , satellite aerosol retrievals are overestimated because of cloud contamination: The aerosol retrievals interpret, in error, cloud droplets as coarse mode particles. Therefore, months with high cloud coverage over megacities are unfavorable for studying relationships between urbanization and satellite-based AOD. In order to minimize the AOD retrieval uncertainty, AOD data were used only for months with cloud fraction less than 0.7 . In order to estimate cloud fraction over megacities, Collection 5 MODISTerra $1^{\circ} \times 1^{\circ}$ and Collection 5.1 MODIS-Aqua $1^{\circ} \times 1^{\circ}$ monthly data of cloud fraction were used.

\subsection{Population Data}

The population of cities, including suburbs, was taken for the year 2010 from Brinkhoff [27] (www.citypopulation.de). In addition, the gridded global population density of World Version 3 (GPWv3) data set of the year 2000, from So- 
cioeconomic Data and Applications Center (SEDAC) of Columbia University, was used

(http://sedac. ciesin.columbia.edu/gpw). The full list of the largest cities examined (including the 26 megacities of over 10 million inhabitants), with information about their population; latitude-longitude coordinates; and countries, is given in Table A1 in the Appendix.

\section{Results}

\subsection{Capability of Satellite Aerosol Sensors in Detecting the Impact of Megacities on AOD}

In order to ensure that satellite aerosol sensors could differentiate between AOD over megacities and over surrounding rural areas, 8-year mean AOD distributions over areas neighboring megacities were analyzed. In particular, we have investigated latitudinal distribution of 8 -year mean AOD over 26 megacities with population exceeding 10 million people. Each latitudinal distribution has an east-west direction and is centered over the megacity center. In order to compare AOD distributions over differing megacities, for each latitudinal distribution, 8 -year mean AOD values were normalized on the 8-year mean AOD over the megacity.

As an example, Figure 1 shows latitudinal distributions of 8-year normalized mean AOD over 13 megacities based on MODIS-Terra (Figure 1(a)) and MODISAqua (Figure 1(b)) data sets. All these distributions show maximum AOD over their megacity which decreases with distance from the megacity. The steepest decreasing slope over some cities, such as Buenos Aires, can be explained by the fact that the city under consideration is surrounded by rural areas. On the other hand, megacities, such as Paris, show a much gentler slope, which can be explained by the presence of other cities and/or industrial centers on the periphery affecting AOD. This makes it more difficult to distinguish the megacity aerosol signature from space. Two independent sensors,

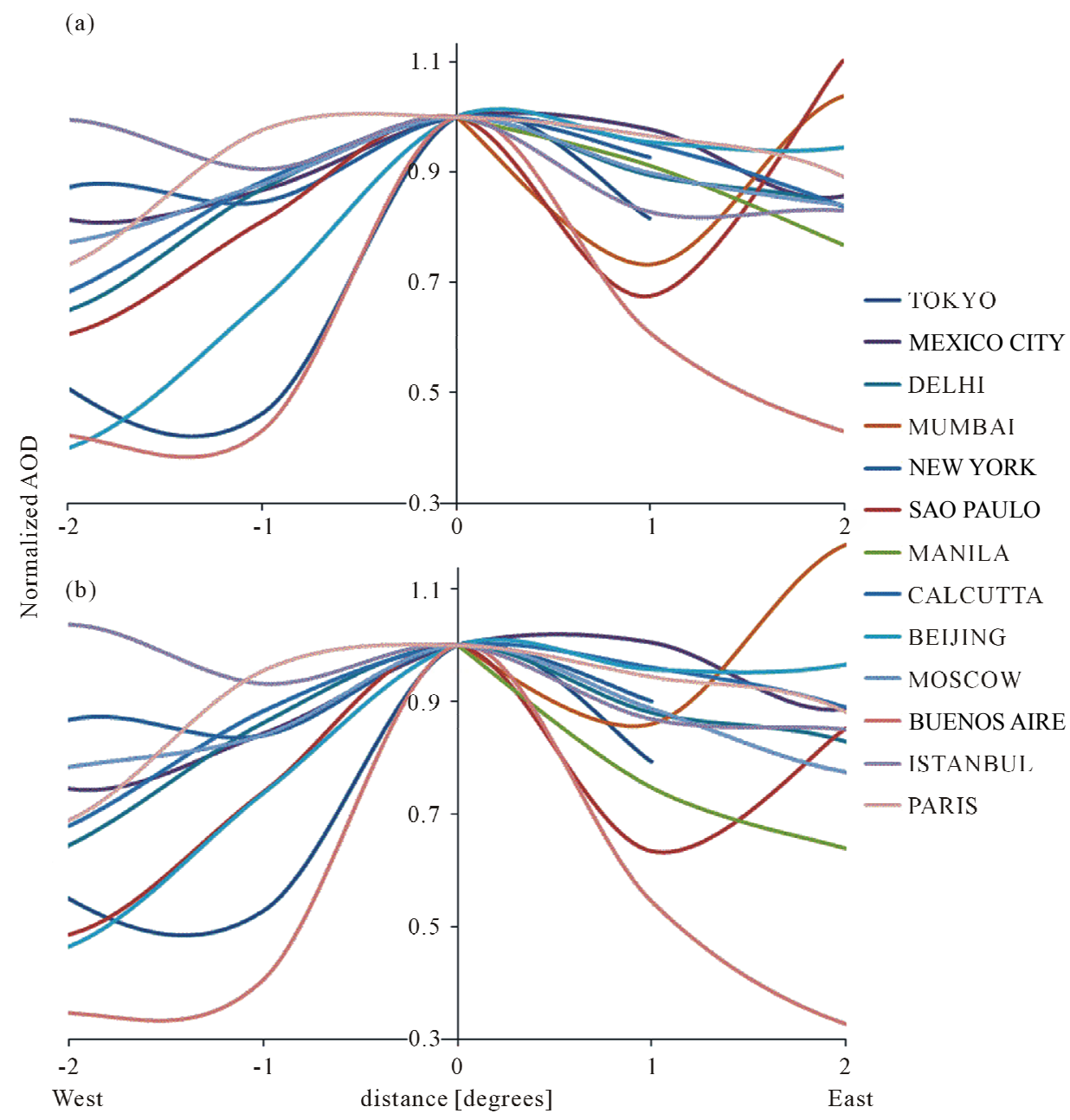

Figure 1. Examples of the latitudinal distribution of 8-year normalized mean AOD over 13 megacities based on (a) MODISTerra and (b) MODIS-Aqua data sets. AOD was normalized on that over the megacity center. List of megacities appears on the right. Further details on population, latitude/longitude etc. are in Table A1. 
MODIS-Terra and MODIS-Aqua, show similar latitudinal distributions of normalized mean AOD over the same megacities.

Figure 2 shows the averaged east-west latitudinal distribution of normalized AOD for all top 26 megacities. The error bars show the standard error of the mean AOD. One can see a clear bell-shaped form, with a maximum over the city center and a decrease away from the city. This indicates that the two MODIS aerosol sensors are able to distinguish between urban and rural areas.

\subsection{Global Distribution of AOD Trends over the Largest Cities in the World}

First, AOD trends were estimated over the fifty-eight largest cities in the world with population exceeding 5 million. The AOD trend values (in percentage form) correspond to the difference between the AOD averaged over the last 4-year period (July 2006-June 2010) and the AOD averaged over the first 4-year period (July 2002June 2006), using as the reference the AOD average over the first period. Based on the resulting AOD tendencies, all the chosen megacities were divided into two groups: One with increasing AOD tendencies and the other with declining AOD tendencies. For each of the two groups we created three sub-groups of cities with tendencies above $10 \%$; from $5 \%$ to $10 \%$; and less than $5 \%$.

The global distribution of resulting AOD tendencies over the 58 chosen cities is shown in Figure 3, where the magnitude and the sign of AOD tendencies are designated by circles of different diameters and colors. Blue shades represent declining AOD tendencies, while orange shades designate increasing tendencies. It is seen that all three sensors (MODIS-Terra, MODIS-Aqua and MISR) show that increasing AOD tendencies are mainly observed over the megacities in the southern and central parts of the Indian subcontinent and North China (Figure 3). Over other areas, including Europe and north-east US,

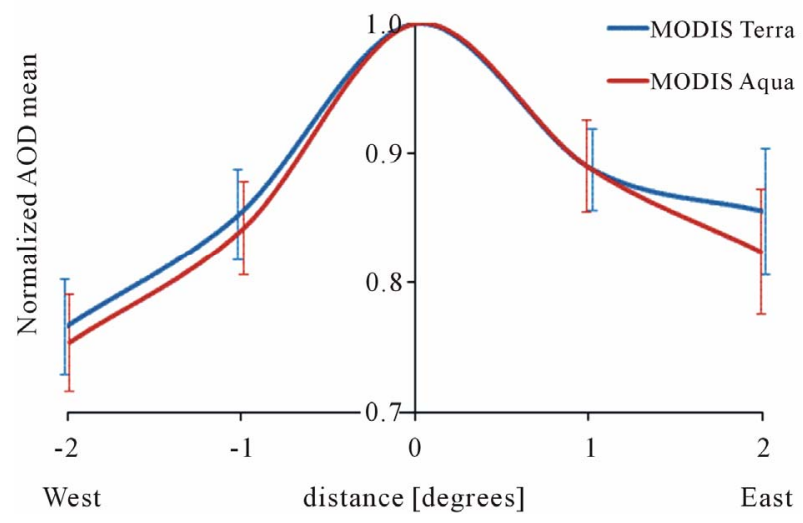

Figure 2. Latitudinal distributions of a normalized AOD averaged over the top 26 megacities. The error bars show the standard error of the mean. the three aforementioned sensors show declining AOD trends. The number of sites limits our ability to identify the predominant AOD trends in some regions. For example, over the north part of the Indian subcontinent, MODIS-Terra shows decreasing AOD trends (Figure 3(a)), while MODIS-Aqua shows weak increasing AOD trends (Figure 3(b)).

However, by examining AOD tendencies over the 189 largest cities in the world with population exceeding 2 million, it was possible to obtain improved details about the global distribution of AOD tendencies.

As shown in Figure 4, increasing AOD tendencies were observed over the majority of sites in the Indian subcontinent, the Middle East, North China, and in the countries of the Gulf of Guinea. By contrast, declining AOD tendencies were dominant over the sites in Europe and the east part of North America, where effective air quality regulation has been established (Figure 4). All three sensors (MODIS-Terra, MODIS-Aqua and MISR) show similar results of the predominant sign of AOD trends over all the aforementioned areas.

In the cases where all three sensors show similar signs of AOD, the results can be considered as reliable. This is supported by the observed trends in surface solar radiation (SSR), obtained by using network pyranometer measurements. In particular, Xia [28] found declining trends in SSR beyond the year 2000 in North China and increasing trends in SSR in South China. As mentioned above, these SSR trends correspond to the obtained increasing AOD trends over North China and decreasing AOD trends over South China. Similarly, Kumari and Goswamy [29] show declining trends in SSR from 1981 to 2006 over the Indian region; these declining SSR trends correspond to the obtained increasing AOD trends there. By contrast, numerous publications discuss increasing trends in surface solar radiation over differing parts of Europe beyond the year 2000 [30-33]. These increasing SSR trends well correspond to the obtained declining AOD trends over Europe.

Zhang and Reid [34] analyzed AOD trends during the recent decade over sea areas downwind from major sources of aerosols on land. They found increasing statistically significant AOD trends over the sea areas surrounding the Indian subcontinent and the east coast of China. Zhang and Reid [34] also found declining statistically insignificant AOD trends over the Mediterranean Sea and near the east coast of North America. There could be some association between their findings over the sea and our findings over megacities. This is because of aerosol transport from land to sea by the action of prevailing winds.

In the cases where the three sensors show differing signs of AOD trends, the results cannot be considered as reliable. For example, in South America, MODIS-Terra 

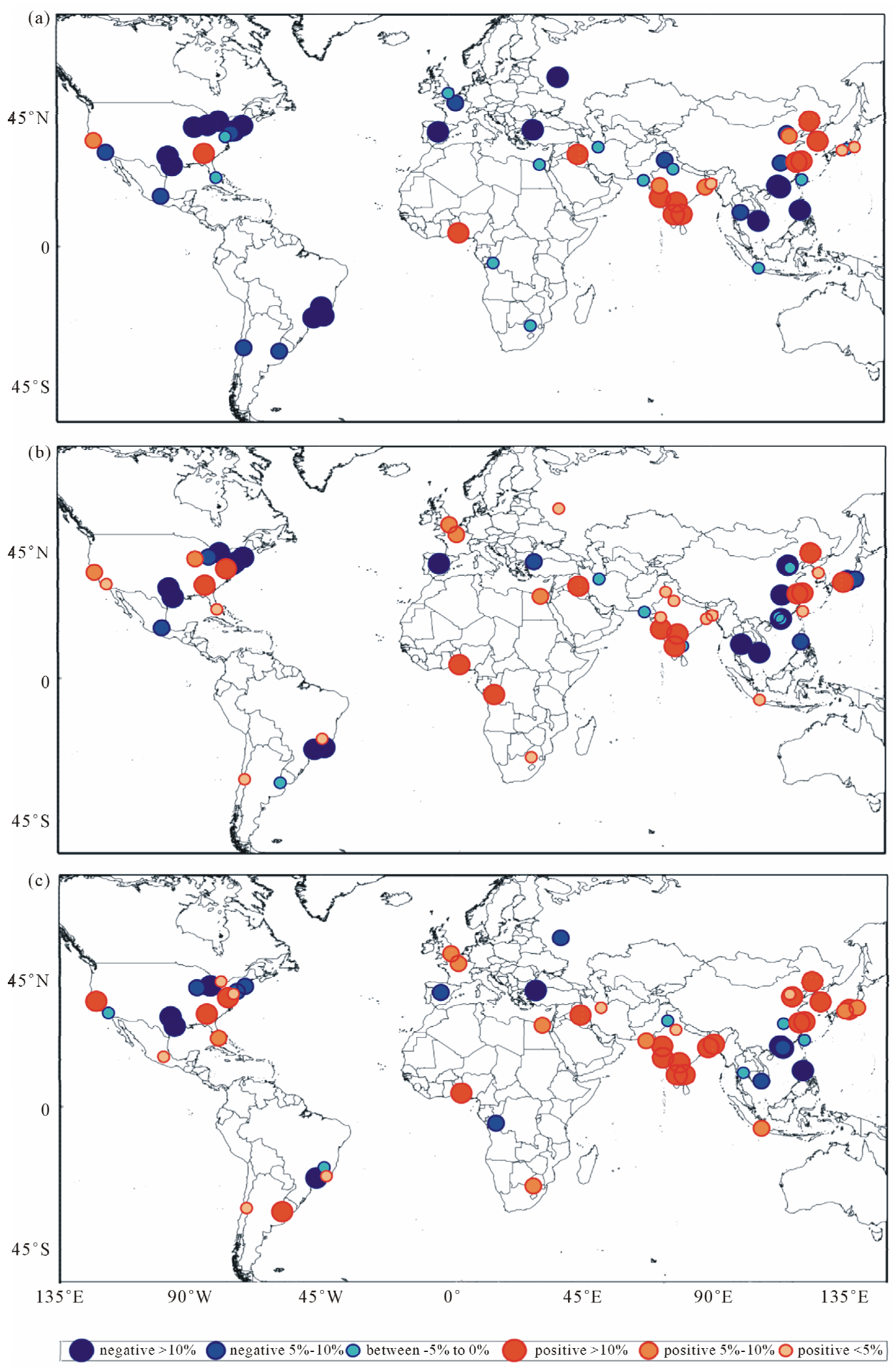

Figure 3. The global distribution of AOD tendencies during the 8-year period 2002-2010 over the 58 largest world cities with population exceeding five million, based on AOD data sets of (a) MODIS-Terra, (b) MODIS-Aqua and (c) MISR. The magnitude and sign of AOD tendencies are designated by circles of different diameters and colors, as shown in the bottom panel. Blue shades designate declining AOD trends, while orange shades designate increasing AOD trends. 

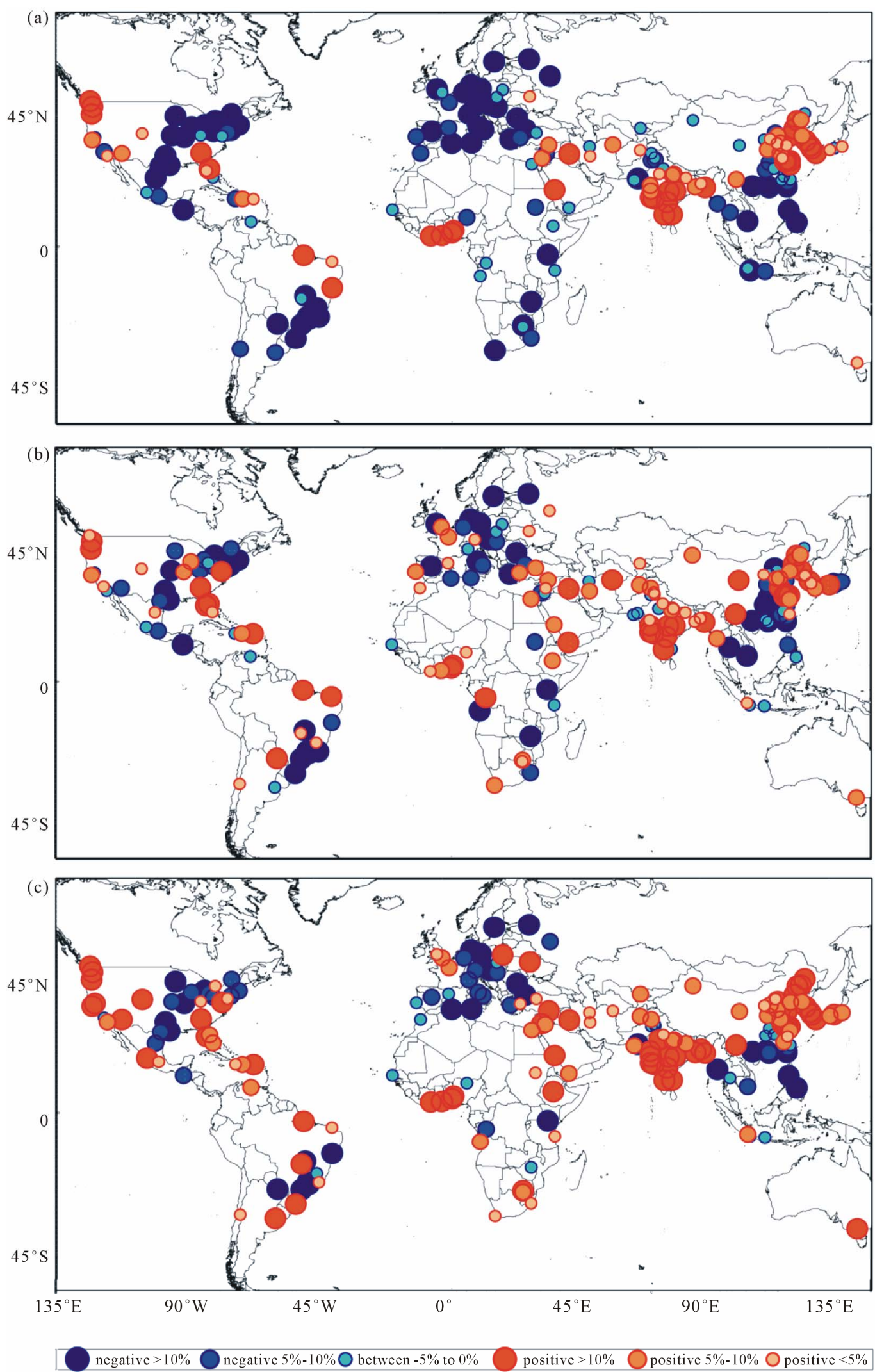

Figure 4. The global distribution of AOD tendencies during the 8-year period 2002-2010 over the 189 largest world cities with population exceeding two million, based on AOD data sets of (a) MODIS-Terra, (b) MODIS-Aqua and (c) MISR. The designnations are the same as in Figure 3. 
shows mainly declining AOD trends, while MISR and MODIS-Aqua show both increasing and declining AOD trends. Unfortunately, we haven't got information about predominant trends in SSR in South America. Therefore, we cannot verify the obtained space-born AOD trends.

It should be noted that the current study focused on signs of AOD trends rather than on their magnitude. So that our conclusions about AOD trends over cities in specific regions were based on the statistics of signs of AOD trends. Note that, even in the regions such as the Indian subcontinent, China, and Europe, where all three sensors showed similar signs of AOD trends over the majority of cities examined, the magnitude of these trends from the three sensors could differ significantly, sometimes by a factor of two or three or even more (Table A1).

In order to study potential biases of the three sensors used, the overall analysis of the distribution of AOD trends obtained for each sensor was conducted (Table 1). It was found that, in total, 1) MODIS-Terra has a shift to the more negative side: MODIS-Terra showed declining AOD trends over $63 \%$ of the cities; 2 ) MODIS-Aqua has a shift to the positive side: MODIS-Aqua showed increasing AOD trends over $60 \%$ of the cities; and 3) MISR has approximately the same number of increasing and declining AOD trends (Table 1). The following additional conclusions can be drawn from Table 1. First, at northern latitudes $\left(15^{\circ} \mathrm{N}-45^{\circ} \mathrm{N}\right)$, the percentage of increasing AOD trends is significantly higher than at southern latitudes $\left(45^{\circ} \mathrm{S}-15^{\circ} \mathrm{S}\right)$. This is particularly strong in MODIS-Terra AOD trends, where, at southern latitudes $45^{\circ} \mathrm{S}-15^{\circ} \mathrm{S}, 95 \%$ of AOD trends were declining, compared to $56 \%$ at northern latitudes $15^{\circ} \mathrm{N}-45^{\circ} \mathrm{N}$. Second, in the Northern hemisphere, at latitudes to the north from $45^{\circ} \mathrm{N}$, the percentage of declining trends drops for all sensors, compared to that at latitudes $15^{\circ} \mathrm{N}$ $45^{\circ} \mathrm{N}$. For example, for MISR, the drop is from $56 \%$ to $38 \%$, while for MODIS-Aqua from $66 \%$ to $38 \%$. Finally, cities at northern latitudes $15^{\circ} \mathrm{N}-45^{\circ} \mathrm{N}$ show higher per- centages of increasing AOT trends than tropical cities at latitudes $15^{\circ} \mathrm{S}-15^{\circ} \mathrm{N}$; the largest drop is for MODISAqua from $66 \%$ to $52 \%$ (Table 1).

\section{Conclusions}

Space monitoring of aerosol optical depth trends over megacities can serve as a potential space indicator of global anthropogenic air-pollution changes. The effects of urbanization on AOD are connected with a high level of anthropogenic aerosol emissions in megacities, in which most of the world population resides and most of the anthropogenic pollution emitted. Space monitoring of AOD trends has the advantage of global coverage and applies the same approach to detecting AOD trends over different sites. Due to the mixing of aerosols loaded by natural and anthropogenic sources, satellite measurements cannot distinguish between natural and anthropogenic aerosols. Assuming that, on average, over megacities, long-term changes in natural aerosols are relatively small compared to those in anthropogenic aerosols, the observed increasing and declining trends can be attributed to changes in anthropogenic aerosols.

Three space aerosol sensors, MODIS-Terra, MODISAqua and MISR, were used in order to study recent decadal trends of AOD over megacities around the world. Note that there are some difficulties with the satellitebased AOD retrievals over land. Levy et al. [19] as well as Zhang and Reid [34] identified a calibration problem with the MODIS blue band that would affect AOD time series analysis for over-land AOD retrievals. Also, MODIS tends to overestimate AOD over bright land surfaces, including urban areas, relative to AERONET (e.g., Levy et al. [19]). Although we are aware of the aforementioned difficulties, we felt that, by using three different sensors, it is possible to obtained valid results. Indeed, in spite of instrumental and time differences among the three sensors investigated, their global pictures of AOD trends over the 189 largest cities in the

Table 1. The distribution of AOD tendencies for each of the three sensors, including the number of cities with increasing and declining AOD tendencies in total and in different latitudinal zones. Percentages of the AOD tendencies are given in parentheses.

\begin{tabular}{|c|c|c|c|c|c|c|}
\hline \multirow{2}{*}{ Sensor } & \multirow{2}{*}{ AOD tendency } & \multicolumn{4}{|c|}{ Latitudinal zones } & \multirow{2}{*}{ Total } \\
\hline & & $45^{\circ} \mathrm{S}-15^{\circ} \mathrm{S}$ & $15^{\circ} \mathrm{S}-15^{\circ} \mathrm{N}$ & $15^{\circ} \mathrm{N}-45^{\circ} \mathrm{N}$ & $>45^{\circ} \mathrm{N}$ & \\
\hline \multirow{2}{*}{ MODIS-Terra } & increasing & $1(5 \%)$ & $9(36 \%)$ & $55(44 \%)$ & $4(19 \%)$ & $69(37 \%)$ \\
\hline & decreasing & $18(95 \%)$ & $16(64 \%)$ & $69(56 \%)$ & $17(81 \%)$ & $120(63 \%)$ \\
\hline \multirow{2}{*}{ MODIS-Aqua } & increasing & $10(53 \%)$ & $13(52 \%)$ & $82(66 \%)$ & $9(43 \%)$ & $114(60 \%)$ \\
\hline & decreasing & $9(47 \%)$ & $12(48 \%)$ & $42(34 \%)$ & $12(57 \%)$ & $75(40 \%)$ \\
\hline \multirow{2}{*}{ MISR } & increasing & $8(42 \%)$ & $11(44 \%)$ & $69(56 \%)$ & $8(38 \%)$ & $96(51 \%)$ \\
\hline & decreasing & $11(58 \%)$ & $14(56 \%)$ & $55(44 \%)$ & $13(62 \%)$ & $93(49 \%)$ \\
\hline
\end{tabular}


world are quite similar. The increasing AOD trends over the largest cities in the Indian subcontinent, the Middle East, and North China can be clearly seen. By contrast, megacities in Europe, the north-east of US, and SouthEast Asia show mainly declining AOD trends.

In the cases where all three sensors show similar signs of AOD trends, the results can be considered as reliable. This is supported by the observed trends in surface solar radiation, obtained by using network pyranometer measurements in North and South China, India, and Europe. In the cases where the three sensors show differing signs of AOD trends (e.g. South America), additional research is required in order to verify the obtained AOD trends.

\section{Acknowledgements}

We gratefully acknowledge the NASA GES-DISC Interactive Online Visualization and Analysis Infrastructure (Giovanni) for providing MODIS and MISR satellite aerosol data. This research was supported by a grant (GLOWAJordan River) from the German Bundesministerium fuer Bildung und Forschung (BMBF); and the Israeli Ministry of Science and Technology (MOST).

\section{REFERENCES}

[1] M. J. Molina and L. T. Molina, "Megacities and Atmospheric Pollution," Journal of the Air \& Waste Management Association, Vol. 54, No. 6, 2004, pp. 644-680. doi:10.1080/10473289.2004.10470936

[2] D. Mage, G. Ozolins, P. Peterson, A. Webster, R. Orthoferj, V. Vandeweerds and M. Gwynnet, "Urban Air Pollution in Megacities of the World," Atmospheric Environment, Vol. 30, No. 5, 1996, pp. 681-686. doi:10.1016/1352-2310(95)00219-7

[3] V. Ramanathan and Y. Feng, "Air Pollution, Greenhouse Gases and Climate Change: Global and Regional Perspectives," Atmospheric Environment, Vol. 43, No. 1, 2009, pp. 37-50. doi:10. 1016/j.atmosenv.2008.09.063

[4] M. L. Bell, D. L. Davis and T. Fletcher, "A Retrospective Assessment of Mortality from the London Smog Episode of 1952: The Role of Influenza and Pollution," Environmental Health Perspectives, Vol. 112, No. 1, 2004, pp. 68. doi:10.1289/ehp.6539

[5] E. H. Decker, S. Elliott, F. A. Smith, D. R. Blake and F. S. Rowland, "Energy and Material Flow through the urban Ecosystem," Annual Review of Energy and the Environment, Vol. 25, 2000, pp. 685-740. doi:10.1146/annurev.energy.25.1.685

[6] E. Samoli, A. Analitis, G. Touloumi, J. Schwartz, H. R. Anderson, J. Sunyer, L. Bisanti, D. Zmirou, J. M. Vonk, J. Pekkanen, P. Goodman, A. Paldy, C. Schindler and K. Katsouyanni, "Estimating the Exposure-Response Relationships between Particulate Matter and Mortality within the APHEA Multicity Project," Environmental Health Perspectives, Vol. 113, No. 1, 2005, pp. 88-95. doi:10.1289/ehp.7387
[7] C. A. Pope, R. T. Burnett, M. J. Thun, E. E. Calle, D. Krewski, K. Ito and G. D. Thurston, "Lung Cancer, Cardiopulmonary Mortality, and Long-Term Exposure to Fine Particulate Air Pollution," The Journal of the American Medical Association, Vol. 287, No. 9, 2002, pp. 1132-1141. doi:10.1001/jama.287.9.1132

[8] V. Ramanathan, et al., "The Indian Ocean Experiment: An Integrated Analysis of the Climate Forcing and Effects of the Great Indo-Asian Haze," Journal of Geophysical Research, Vol. 106, No. D22, 2001, pp. 28371 28398. doi:10.1029/2001JD900133

[9] V. Ramanathan, P. J. Crutzen, J. T. Kiehl and D. Rosenfeld, "Aerosols, Climate, and the Hydrological Cycle," Science, Vol. 294, No. 5549, 2001, pp. 2119-2124. doi:10.1126/science.1064034

[10] Y. J. Kaufman, D. Tanré and O. Boucher, “A Satellite View of Aerosols in the Climate System," Nature, Vol. 419, 2002, pp. 215-223. doi:10.1038/nature01091

[11] G. Stanhill and S. Cohen, "Global Dimming: A Review of the Evidence for a Widespread and Significant Reduction in Global Radiation with Discussion of Its Probable Causes and Possible Agricultural Consequences," Agricultural and Forest Meteorology, Vol. 107, No. 4, 2001, pp. 255-278. doi:10.1016/S0168-1923(00)00241-0

[12] M. Wild, "Global Dimming and Brightening: A Review," Journal of Geophysical Research, Vol. 114, 2009, Article ID: D00D16. doi:10.1029/2008JD011470

[13] P. Alpert, P. Kishcha, Y. J. Kaufman and R. Schwarzbard, "Global Dimming or Local Dimming: Effect of Urbanization on Sunlight Availability," Geophysical Research Letters, Vol. 32, 2005, Article ID: L17802. doi:10.1029/2005GL023320

[14] P. Alpert and P. Kishcha, "Quantification of the Effect of Urbanization on Solar Dimming," Geophysical Research Letters, Vol. 35, 2008, Article ID: L08801. doi:10.1029/2007GL033012

[15] P. Kishcha, B. Starobinets, O. Kalashnikova and P. Alpert, "Aerosol Optical Thickness Trends and Population Growth in the Indian Subcontinent," International Journal of Remote Sensing, Vol. 32, No. 24, 2011, pp. 9137-9149. doi: $10.1080 / 01431161.2010 .550333$

[16] D. J. Diner, J. C. Beckert, T. H. Reilly, C. J. Bruegge, J. E. Conel, R. A. Kahn, J. V. Martonchik, T. P. Ackerman, R. Davies, S. A. W. Gerstl, H. R. Gordon, J.-P. Muller, R. Myneni, P. J. Sellers, B. Pinty and M. M. Verstraete, "Multiangle Imaging Spectroradiometer (MISR) Instrument Description and Experiment Overview," IEEE Transactions on Geoscience and Remote Sensing, Vol. 36, No. 4, 1998, pp. 1072-1087. doi:10.1109/36.700992

[17] O. V. Kalashnikova and R. Kahn, "Mineral Dust Plume Evolution over the Atlantic from MISR and MODIS Aerosol Retrievals," Journal of Geophysical Research, Vol. 113, 2009, Article ID: D24204. doi:10.1029/2008JD010083

[18] L. A. Remer, Y. J. Kaufman, D. Tanré, S. Mattoo, D. A. Chu, J. V. Martins, R.-R. Li, C. Ichoku, R. C. Levy, R. G. Kleidman, T. F. Eck, E. Vermote and B. N. Holben, "The MODIS Aerosol Algorithm, Products and Validation," Journal of the Atmospheric Sciences, Vol. 62, No. 4, 
2005, pp. 947-973. doi:10.1175/JAS3385.1

[19] R. C. Levy, L. A. Remer, R. G. Kleidman, S. Mattoo, C. Ichoku, R. Kahn and T. E. Eck, "Global Evaluation of the Collection 5 MODIS Dark-Target Aerosol Products over Land," Atmospheric Chemistry and Physics, Vol. 10, 2010, pp. 10399-10420. doi:10.5194/acp-10-10399-2010

[20] Y. Liu, J. A. Sarnat, B. A. Coull, P. Koutrakis and D. J. Jacob, "Validation of Multiangle Imaging Spectroradiometer (MISR) Aerosol Optical Thickness Measurements Using Aerosol Robotic Network (AERONET) Observations over the Contiguous United States," Journal of Geophysical Research, Vol. 109, 2004, Article ID: D06205. doi:10.1029/2003JD003981

[21] M. M. Oo, M. Jerg, E. Hernandez, A. Picon, B. M. Gross, F. Moshary and S. A. Ahmed, "Improved MODIS Aerosol Retrieval Using Modified VIS/SWIR Surface Albedo Ratio over Urban Scenes," IEEE Transactions on Geoscience and Remote Sensing, Vol. 48, No. 3, 2010, pp. 9831000. doi:10.1109/TGRS.2009.2028333

[22] S. N. Tripathi, S. Day, A. Chandel, S. Srivastava, R. P. Singh and B. Holben, "Comparison of MODIS and AERONET Derived Aerosol Optical Depth over the Ganga Basin, India," Annales Geophysicae, Vol. 23, 2005, pp. 1093-1101. doi:10.5194/angeo-23-1093-2005

[23] J. Zhang, J. S. Reid and B. N. Holben, “An Analysis of Potential Cloud Artifacts in MODIS over Ocean Aerosol Optical Thickness Products," Geophysical Research Letters, Vol. 32, 2005, Article ID: L15803. doi:10.1029/2005GL023254

[24] I. Koren, L. Remer, Y. Kaufman, Y. Rudich and J. Martins, "On the Twilight Zone between Clouds and Aerosols," Geophysical Research Letters, Vol. 34, 2007, Article ID: L08805. doi:10.1029/2007GL029253

[25] A. K. Prasad and R. P. Singh, "Comparison of MISRMODIS Aerosol Optical Depth over the Indo-Gangetic Basin during the Winter and Summer Seasons (20002005)," Remote Sensing of Environment, Vol. 107, No. 12, 2007, pp. 109-119. doi:10.1016/j.rse.2006.09.026

[26] L. A. Remer, R. G. Kleidman, R. C. Levy, Y. J. Kaufman, D. Tanré, S. Mattoo, J. V. Martins, C. Ichoku, I. Koren, H.
$\mathrm{Yu}$ and B. Holben, "Global Aerosol Climatology from the MODIS Satellite Sensors," Journal of Geophysical Research, Vol. 113, 2008, Article ID: D14S07. doi:10.1029/2007JD009661

[27] T. Brinkhoff, "The Principal Agglomerations of the World," 2010. http://www.citypopulation.de

[28] X. Xia, "A Closer Looking at Dimming and Brightening in China during 1961-2005," Annales Geophysicae, Vol. 28, 2010, pp. 1121-1132. doi:10.5194/angeo-28-1121-2010

[29] B. P. Kumari and B. N. Goswami, "Seminal Role of Clouds on Solar Dimming over the Indian Monsoon Region," Geophysical Research Letters, Vol. 37, 2010, Article ID: L06703. doi:10.1029/2009GL042133

[30] K. Makowski, E. B. Jaeger, M. Chiacchio, M. Wild, T. Ewen and A. Ohmura, "On the Relationship between Diurnal Temperature Range and Surface Solar Radiation in Europe," Journal of Geophysical Research, Vol. 114, 2009, Article ID: D00D07. doi:10.1029/2008JD011104

[31] J. R. Norris and M. Wild, "Trends in Aerosol Radiative Effects over Europe Inferred from Observed Cloud Cover, Solar 'Dimming' and Solar 'Brightening,,' Journal of Geophysical Research, Vol. 112, 2007, Article ID: D08214. doi:10.1029/2006JD007794

[32] C. W. Strjern, J. E. Kristjansson and A. W. Hansen, "Global Dimming and Global Brightening-An Analysis of Surface Radiation and Cloud Cover Data in Northern Europe," International Journal of Climatology, Vol. 29, No. 5, 2008. doi:10.1002/joc. 1735

[33] A. Sanchez-Lorenzo and M. Wild, "Decadal Variations in Estimated Surface Solar Radiation over Switzerland since the Late 19th Century," Atmospheric Chemistry and Physics Discussions, Vol. 12, 2012, pp. 10815-10843. doi:10.5194/acpd-12-10815-2012

[34] J. Zhang and J. S. Reid, "A Decadal Regional and Global Trend Analysis of the Aerosol Optical Depth Using a Data-Assimilation Grade Over-Water MODIS and Level 2 MISR Aerosol Products," Atmospheric Chemistry and Physics, Vol. 10, 2010, pp. 10949-10963. doi:10.5194/acp-10-10949-2010 


\section{Appendix}

Table A1. List of the world largest cities sorted by population in descending order, including population numbers, latitude, longitude, and AOD tendencies.

\begin{tabular}{|c|c|c|c|c|c|c|c|c|}
\hline \multirow{2}{*}{ No. } & \multirow{2}{*}{$\begin{array}{l}\text { Population } \\
\text { [millions] }\end{array}$} & \multirow{2}{*}{ Country } & \multirow{2}{*}{ City } & \multirow{2}{*}{$\begin{array}{l}\text { Latitude } \\
\text { [degrees] }\end{array}$} & \multirow{2}{*}{$\begin{array}{c}\text { Longitude } \\
\text { [degrees] }\end{array}$} & \multicolumn{3}{|c|}{ AOD tendencies [\%] } \\
\hline & & & & & & MODIS-Terra & MISR & MODIS-Aqua \\
\hline 1 & 34.00 & Japan & Tokyo & 35.70 & 139.72 & 0.4 & -5.5 & 6.7 \\
\hline 2 & 24.20 & Korea (South) & Seoul & 37.57 & 126.98 & 12.0 & 0.4 & 17.1 \\
\hline 3 & 24.20 & China & Canton (Guangzhou) & 23.13 & 113.26 & -17.5 & -2.7 & -18.2 \\
\hline 4 & 23.40 & Mexico & Mexico City & 19.43 & -99.13 & -8.8 & -5.5 & 1.4 \\
\hline 5 & 23.20 & India & Delhi & 28.61 & 77.23 & -1.8 & 0.1 & 1.1 \\
\hline 6 & 22.80 & India & Mumbai & 18.98 & 72.83 & 14.7 & 17.7 & 20.7 \\
\hline 7 & 22.20 & USA & New York & 40.72 & -74.00 & -15.5 & -14.9 & -8.3 \\
\hline 8 & 20.90 & Brazil & Sao Paulo & -23.55 & -46.63 & -17.2 & -16.7 & -11.8 \\
\hline 9 & 19.60 & Philippines & Manila & 14.58 & 120.97 & -20.6 & -9.1 & -10.1 \\
\hline 10 & 18.40 & China & Shanghai & 31.20 & 121.50 & 17.0 & 10.3 & 13.9 \\
\hline 11 & 17.90 & USA & Los Angeles & 34.05 & -118.25 & -8.9 & 1.7 & 0.0 \\
\hline 12 & 16.80 & Japan & Osaka & 34.67 & 135.50 & 3.9 & 52.7 & 5.9 \\
\hline 13 & 16.30 & India & Calcutta & 22.57 & 88.37 & 7.6 & 3.6 & 11.5 \\
\hline 14 & 16.20 & Pakistan & Karachi & 24.86 & 67.01 & -0.4 & -1.1 & 5.1 \\
\hline 15 & 15.40 & Indonesia & Jakarta & -6.13 & 106.75 & -1.1 & 3.5 & 6.2 \\
\hline 16 & 15.20 & Egypt & Cairo & 30.06 & 31.23 & -2.7 & 6.3 & 8.4 \\
\hline 17 & 13.60 & China & Beijing & 39.91 & 116.39 & -5.5 & -22.0 & 1.1 \\
\hline 18 & 13.60 & Bangladesh & Dhaka & 23.70 & 90.38 & 4.3 & 2.9 & 11.1 \\
\hline 19 & 13.60 & Russia & Moscow & 55.75 & 37.62 & -17.5 & 2.8 & -8.1 \\
\hline 20 & 13.30 & Argentina & Buenos Aires & -34.60 & -58.38 & -8.2 & -2.7 & 14.5 \\
\hline 21 & 12.80 & Iran & Tehran & 35.70 & 51.42 & -3.5 & -1.2 & 1.9 \\
\hline 22 & 12.80 & Turkey & Istanbul & 41.02 & 28.97 & -16.1 & -8.0 & -12.2 \\
\hline 23 & 12.60 & Brazil & Rio De Janeiro & -22.91 & -43.20 & -28.4 & -18.2 & 4.1 \\
\hline 24 & 12.40 & Great Britain & London & 51.51 & -0.12 & -4.7 & 8.4 & 7.9 \\
\hline 25 & 11.80 & Nigeria & Lagos & 6.45 & 3.40 & 17.6 & 11.0 & 17.8 \\
\hline 26 & 10.40 & France & Paris & 48.86 & 2.35 & -8.1 & 5.0 & 9.8 \\
\hline 27 & 9.85 & USA & Chicago & 41.84 & -87.68 & -17.7 & 8.2 & -8.2 \\
\hline 28 & 9.15 & China & Shenzhen & 22.55 & 114.10 & -16.0 & -14.1 & -6.9 \\
\hline 29 & 8.95 & China & Wuhan & 30.57 & 114.28 & -8.8 & -16.9 & -1.3 \\
\hline 30 & 8.90 & Thailand & Bangkok & 13.75 & 100.49 & -5.2 & -11.3 & -3.0 \\
\hline 31 & 8.90 & Congo (Dem. Rep.) & Kinshasa & -4.31 & 15.32 & -4.4 & 12.7 & -5.2 \\
\hline 32 & 8.55 & Pakistan & Lahore & 31.55 & 74.34 & -5.6 & 2.6 & -1.6 \\
\hline 33 & 8.35 & Japan & Nagoya & 35.17 & 136.92 & -0.9 & -20.6 & 10.2 \\
\hline
\end{tabular}


Continued

\begin{tabular}{|c|c|c|c|c|c|c|c|c|}
\hline 34 & 8.35 & China & Tientsin & 39.13 & 117.20 & 6.0 & -2.3 & 13.1 \\
\hline 35 & 8.25 & USA & Washington & 38.90 & -77.04 & -4.3 & 10.7 & 12.3 \\
\hline 36 & 8.20 & India & Madras & 13.08 & 80.28 & 13.1 & -0.4 & 13.5 \\
\hline 37 & 7.80 & India & Bangalore & 12.98 & 77.58 & 23.3 & 12.9 & 66.0 \\
\hline 38 & 7.55 & South Africa & Johannesburg & -26.20 & 28.08 & -4.7 & 1.9 & 6.7 \\
\hline 39 & 7.50 & India & Hyderabad & 17.38 & 78.47 & 18.9 & 26.6 & 34.5 \\
\hline 40 & 7.45 & USA & San Francisco & 37.76 & -122.44 & 8.0 & 6.6 & 19.7 \\
\hline 41 & 7.05 & China & Hong Kong & 22.38 & 114.13 & -24.4 & -2.8 & -13.2 \\
\hline 42 & 6.80 & China & Shenyang & 43.63 & 124.05 & 13.4 & 10.6 & 20.9 \\
\hline 43 & 6.80 & Taiwan & Taipei & 25.05 & 121.53 & -0.8 & 3.3 & -3.9 \\
\hline 44 & 6.60 & Iraq & Baghdad & 33.34 & 44.39 & 16.7 & 15.2 & 25.4 \\
\hline 45 & 6.50 & USA & Dallas & 32.80 & -96.79 & -35.2 & -10.5 & -14.0 \\
\hline 46 & 6.20 & Spain & Madrid & 40.42 & -3.71 & -18.3 & -10.0 & -7.4 \\
\hline 47 & 6.10 & Vietnam & Saigon & 10.75 & 106.67 & -16.2 & -12.1 & -6.2 \\
\hline 48 & 6.00 & USA & Philadelphia & 40.00 & -75.14 & -10.0 & -10.1 & 4.5 \\
\hline 49 & 6.00 & Chile & Santiago & -33.45 & -70.67 & -9.5 & 3.1 & 0.7 \\
\hline 50 & 5.95 & India & Ahmedabad & 23.03 & 72.62 & 8.6 & 4.5 & 13.2 \\
\hline 51 & 5.90 & Brazil & Belo Horizonte & -19.92 & -43.93 & -38.4 & 0.5 & -1.4 \\
\hline 52 & 5.90 & USA & Houston & 29.76 & -95.38 & -39.6 & -22.2 & -30.5 \\
\hline 53 & 5.85 & China & Sian & 30.90 & 119.65 & 12.1 & 13.6 & 13.6 \\
\hline 54 & 5.75 & USA & Boston & 42.32 & -71.09 & -19.2 & -11.9 & -6.5 \\
\hline 55 & 5.75 & Canada & Toronto & 43.67 & -79.42 & -13.4 & -14.3 & 2.6 \\
\hline 56 & 5.70 & USA & Atlanta & 33.76 & -84.40 & 34.8 & 11.4 & 41.6 \\
\hline 57 & 5.55 & USA & Detroit & 42.39 & -83.10 & -15.7 & -8.5 & -10.6 \\
\hline 58 & 5.40 & USA & Miami & 25.79 & -80.22 & -3.8 & 1.2 & 5.8 \\
\hline 59 & 4.98 & Sudan & Khartoum & 15.59 & 32.53 & -6.9 & -6.5 & 3.8 \\
\hline 60 & 4.85 & India & Poona & 18.53 & 73.87 & 19.8 & 23.8 & 34.0 \\
\hline 61 & 4.80 & China & Nanking & 32.05 & 118.77 & 3.5 & -11.7 & 10.5 \\
\hline 62 & 4.78 & Russia & St. Petersburg & 59.89 & 30.26 & -30.6 & -12.4 & -26.1 \\
\hline 63 & 4.73 & Myanmar & Rangoon & 16.79 & 96.15 & -9.1 & 6.1 & -15.1 \\
\hline 64 & 4.68 & Germany & The Ruhr & 51.50 & 7.50 & -15.7 & -9.3 & -9.3 \\
\hline 65 & 4.63 & Bangladesh & Chittagong & 22.36 & 91.80 & 25.2 & 26.8 & 31.2 \\
\hline 66 & 4.63 & Mexico & Guadalajara & 20.67 & -103.33 & -4.9 & -2.8 & 12.0 \\
\hline 67 & 4.60 & China & Shantou & 33.70 & 118.10 & 7.5 & 45.6 & 7.4 \\
\hline 68 & 4.48 & Australia & Sydney & -33.87 & 151.21 & -2.2 & -19.1 & -8.5 \\
\hline 69 & 4.40 & Cote D'ivoire & Abidjan & 5.32 & -4.03 & 16.9 & 2.2 & 20.2 \\
\hline 70 & 4.40 & China & Harbin & 45.75 & 126.63 & -0.6 & -2.5 & 15.5 \\
\hline
\end{tabular}




\section{Continued}

\begin{tabular}{|c|c|c|c|c|c|c|c|c|}
\hline 71 & 4.40 & USA & Phoenix & 33.53 & -112.08 & 6.3 & -5.8 & 11.3 \\
\hline 72 & 4.33 & Germany & Berlin & 52.52 & 13.38 & -20.5 & -17.9 & -12.3 \\
\hline 73 & 4.33 & Venezuela & Caracas & 10.50 & -66.92 & -2.9 & -2.7 & 7.9 \\
\hline 74 & 4.30 & Spain & Barcelona & 41.40 & 2.17 & -8.8 & 4.2 & -2.3 \\
\hline 75 & 4.23 & India & Surat & 21.17 & 72.83 & 7.3 & 12.3 & 14.7 \\
\hline 76 & 4.15 & Mexico & Monterrey & 25.66 & -100.31 & -15.9 & 1.5 & -5.3 \\
\hline 77 & 4.13 & Brazil & Porto Alegre & -30.03 & -51.20 & -20.3 & -26.0 & 15.6 \\
\hline 78 & 4.03 & USA & Seattle & 47.63 & -122.33 & 19.5 & 16.0 & 60.4 \\
\hline 79 & 4.00 & Turkey & Ankara & 39.92 & 32.83 & -2.6 & 6.9 & 1.6 \\
\hline 80 & 4.00 & Australia & Melbourne & -37.81 & 144.96 & 2.5 & 5.2 & 20.2 \\
\hline 81 & 3.98 & Morocco & Casablanca & 33.59 & -7.62 & -7.0 & 0.5 & -0.2 \\
\hline 82 & 3.95 & Brazil & Salvador & -12.97 & -38.50 & 24.3 & -8.9 & -25.7 \\
\hline 83 & 3.85 & Brazil & Brasília & -15.78 & -47.92 & -27.9 & -15.7 & -17.0 \\
\hline 84 & 3.83 & China & Tsingtao & 36.08 & 120.33 & 0.8 & -9.9 & 10.2 \\
\hline 85 & 3.78 & Greece & Athens & 37.98 & 23.73 & -14.2 & -12.3 & -6.2 \\
\hline 86 & 3.78 & South Africa & Cape Town & -33.92 & 18.42 & -11.6 & 9.5 & 1.3 \\
\hline 87 & 3.78 & Canada & Montreal & 45.57 & -73.66 & -17.1 & -5.2 & -9.6 \\
\hline 88 & 3.73 & Brazil & Fortaleza & -3.78 & -38.59 & 3.5 & 29.8 & 4.9 \\
\hline 89 & 3.68 & Korea (South) & Pusan & 35.10 & 129.04 & 18.9 & 2.1 & 28.0 \\
\hline 90 & 3.68 & India & Kanpur & 26.47 & 80.35 & 5.1 & 7.5 & 5.5 \\
\hline 91 & 3.65 & South Africa & Durban & -29.85 & 31.02 & -9.1 & -9.9 & 1.0 \\
\hline 92 & 3.58 & Ghana & Accra & 5.55 & -0.22 & 10.5 & 8.5 & 12.4 \\
\hline 93 & 3.58 & Italy & Milan & 45.48 & 9.19 & -16.0 & -2.8 & -8.5 \\
\hline 94 & 3.55 & Italy & Rome & 41.89 & 12.50 & -13.7 & -15.4 & -8.9 \\
\hline 95 & 3.50 & Kenya & Nairobi & -1.28 & 36.82 & -28.7 & -10.2 & -17.7 \\
\hline 96 & 3.48 & China & Dairen & 38.92 & 121.64 & 12.9 & 9.5 & 9.6 \\
\hline 97 & 3.45 & China & Changchun & 43.87 & 125.35 & 5.0 & 6.8 & 20.5 \\
\hline 98 & 3.45 & USA & Minneapolis & 44.96 & -93.27 & -20.9 & -6.7 & -14.3 \\
\hline 99 & 3.43 & Ukraine & Kiev & 50.44 & 30.52 & 4.3 & 2.9 & 14.2 \\
\hline 100 & 3.40 & Brazil & Curitiba & -25.42 & -49.25 & -29.9 & -15.6 & -33.0 \\
\hline 101 & 3.38 & Nigeria & Ibadan & 7.39 & 3.90 & 37.5 & 11.9 & 35.9 \\
\hline 102 & 3.38 & China & Jinan & 36.67 & 116.98 & 2.8 & 6.0 & 7.1 \\
\hline 103 & 3.38 & Nigeria & Kano & 12.00 & 8.52 & -6.3 & 0.8 & -3.1 \\
\hline 104 & 3.35 & Saudi Arabia & Jidda & 21.52 & 39.22 & 11.9 & 5.5 & 21.5 \\
\hline 105 & 3.33 & Pakistan & Lyallpur & 31.42 & 73.08 & -6.0 & -2.8 & -2.3 \\
\hline 106 & 3.28 & India & Jaipur & 26.92 & 75.82 & 3.8 & -1.5 & 13.1 \\
\hline 107 & 3.28 & Dominican Republic & Santo Domingo & 18.47 & -69.90 & 5.1 & 9.5 & 7.8 \\
\hline
\end{tabular}


Continued

\begin{tabular}{|c|c|c|c|c|c|c|c|c|}
\hline 108 & 3.25 & Indonesia & Bandung & -6.90 & 107.58 & -10.8 & -4.1 & -3.4 \\
\hline 109 & 3.23 & Tanzania & Dar Es Salaam & -6.88 & 39.30 & -3.0 & -2.2 & 3.8 \\
\hline 110 & 3.23 & Pakistan & Rawalpindi & 33.60 & 73.07 & -1.7 & 8.4 & 5.5 \\
\hline 111 & 3.23 & China & Taiyuan & 37.87 & 112.56 & -2.1 & 0.9 & 4.8 \\
\hline 112 & 3.20 & China & Kunming & 25.07 & 102.68 & 10.0 & 15.0 & 26.5 \\
\hline 113 & 3.18 & Algeria & Algiers & 36.70 & 3.22 & -19.3 & -8.1 & -14.2 \\
\hline 114 & 3.15 & China & Zhengzhou & 34.77 & 113.65 & 5.0 & -8.1 & 7.1 \\
\hline 115 & 3.10 & Ethiopia & Addis Abeba & 9.03 & 38.70 & -0.3 & 8.4 & 16.6 \\
\hline 116 & 3.10 & China & Fuzhou & 26.08 & 119.31 & -2.4 & -1.2 & 9.2 \\
\hline 117 & 3.10 & Angola & Luanda & -8.84 & 13.23 & -1.1 & -17.5 & 5.1 \\
\hline 118 & 3.10 & Italy & Naples & 40.85 & 14.27 & -11.5 & -7.5 & -6.2 \\
\hline 119 & 3.03 & USA & San Diego & 32.78 & -117.15 & 1.7 & -2.2 & 5.2 \\
\hline 120 & 3.00 & Indonesia & Surabaya & -7.25 & 112.75 & -9.8 & -3.1 & -4.4 \\
\hline 121 & 2.98 & Jordan & Amman & 31.95 & 35.93 & -1.0 & -4.4 & 6.2 \\
\hline 122 & 2.95 & India & Lucknow & 26.85 & 80.92 & 5.1 & 4.4 & 5.5 \\
\hline 123 & 2.93 & Guatemala & Guatemala City & 14.63 & -90.52 & -25.0 & -15.2 & -9.0 \\
\hline 124 & 2.93 & Afghanistan & Kabul & 34.53 & 69.17 & 2.5 & 6.0 & 9.1 \\
\hline 125 & 2.90 & Syria & Aleppo & 36.20 & 37.17 & 7.9 & 9.2 & 16.5 \\
\hline 126 & 2.90 & Turkey & Izmir & 38.42 & 27.17 & -5.4 & 8.2 & 2.5 \\
\hline 127 & 2.88 & USA & Denver & 39.73 & -104.97 & 4.5 & 3.3 & 19.5 \\
\hline 128 & 2.85 & USA & St. Louis & 38.63 & -90.24 & -20.5 & 9.1 & -11.4 \\
\hline 129 & 2.83 & Brazil & Campinas & -22.90 & -47.08 & -22.1 & -22.5 & -13.1 \\
\hline 130 & 2.83 & India & Nagpur & 21.15 & 79.10 & 14.6 & 14.2 & 25.1 \\
\hline 131 & 2.80 & Taiwan & Kaohsiung & 22.63 & 120.35 & -14.4 & -17.1 & -11.0 \\
\hline 132 & 2.78 & China & Changsha & 28.20 & 112.97 & -7.1 & -29.8 & -5.0 \\
\hline 133 & 2.78 & USA & Cleveland & 41.48 & -81.67 & -15.7 & -2.9 & -9.5 \\
\hline 134 & 2.75 & USA & Tampa & 27.97 & -82.46 & 2.9 & 24.1 & 14.4 \\
\hline 135 & 2.73 & Puerto Rico & San Juan & 18.41 & -66.06 & 3.9 & 13.4 & 11.6 \\
\hline 136 & 2.70 & Syria & Damascus & 33.50 & 36.30 & -9.5 & 3.5 & -2.6 \\
\hline 137 & 2.70 & Iran & Meshed & 36.26 & 59.56 & 6.9 & 22.2 & 4.5 \\
\hline 138 & 2.68 & Senegal & Dakar & 14.72 & -17.48 & -0.8 & -2.5 & -1.5 \\
\hline 139 & 2.68 & USA & Orlando & 28.53 & -81.38 & 15.2 & 30.6 & 5.2 \\
\hline 140 & 2.68 & Korea (North) & Pyongyang & 39.02 & 125.75 & 5.7 & 12.5 & 9.9 \\
\hline 141 & 2.63 & Great Britain & Birmingham & 52.47 & -1.92 & -12.3 & -22.1 & 3.4 \\
\hline 142 & 2.63 & Korea (South) & Taegu & 35.87 & 128.60 & 15.7 & 20.1 & 23.5 \\
\hline 143 & 2.60 & Germany & Hamburg & 53.55 & 10.00 & -24.4 & -23.0 & -11.5 \\
\hline 144 & 2.60 & Haiti & Port-Au-Prince & 18.54 & -72.34 & -8.6 & -2.1 & 4.6 \\
\hline
\end{tabular}


Continued

\begin{tabular}{|c|c|c|c|c|c|c|c|c|}
\hline 145 & 2.58 & China & Shijiazhuang & 38.04 & 114.50 & 4.9 & -3.5 & 5.4 \\
\hline 146 & 2.58 & China & Wenzhou & 28.00 & 120.66 & -2.2 & -5.9 & 3.3 \\
\hline 147 & 2.55 & Portugal & Lisbon & 38.72 & -9.14 & -5.3 & 7.6 & -0.6 \\
\hline 148 & 2.55 & China & Suzhou & 31.30 & 120.60 & 14.7 & 14.7 & 13.5 \\
\hline 149 & 2.53 & India & Patna & 25.60 & 85.12 & 4.4 & 2.1 & 8.0 \\
\hline 150 & 2.53 & South Africa & Pretoria & -25.75 & 28.20 & -10.4 & 5.2 & 10.1 \\
\hline 151 & 2.50 & Uzbekistan & Tashkent & 41.32 & 69.25 & -0.3 & 1.5 & 7.5 \\
\hline 152 & 2.50 & China & Zibo & 36.78 & 118.05 & 5.9 & 7.6 & 14.2 \\
\hline 153 & 2.48 & Poland & Katowice & 50.26 & 19.02 & -2.6 & -1.6 & -4.8 \\
\hline 154 & 2.45 & Philippines & Cebu & 10.32 & 123.90 & -12.3 & -4.3 & -20.8 \\
\hline 155 & 2.43 & Japan & Fukuoka & 33.50 & 130.50 & 13.2 & 9.7 & 29.2 \\
\hline 156 & 2.38 & China & Urumqi & 43.73 & 87.57 & -1.8 & 5.6 & 7.6 \\
\hline 157 & 2.38 & Canada & Vancouver & 49.27 & -123.15 & 15.5 & 4.4 & 53.4 \\
\hline 158 & 2.35 & USA & Pittsburgh & 40.44 & -79.98 & -26.9 & -5.8 & -8.7 \\
\hline 159 & 2.33 & China & Lanzhou & 36.05 & 103.80 & -2.4 & 19.4 & 8.7 \\
\hline 160 & 2.33 & Tunisia & Tunis & 36.80 & 10.18 & -17.1 & -9.8 & -11.7 \\
\hline 161 & 2.30 & China & Anshan & 41.11 & 122.98 & 17.5 & 17.3 & 24.6 \\
\hline 162 & 2.30 & Hungary & Budapest & 47.50 & 19.08 & -12.7 & -9.2 & -7.1 \\
\hline 163 & 2.30 & Zimbabwe & Harare & -17.83 & 31.05 & -24.8 & -20.0 & -0.9 \\
\hline 164 & 2.30 & USA & Sacramento & 38.56 & -121.47 & -2.5 & -4.4 & 20.1 \\
\hline 165 & 2.28 & Taiwan & Taichung & 24.25 & 120.72 & -6.9 & -6.4 & -8.1 \\
\hline 166 & 2.28 & Israel & Tel Aviv-Jaffa & 32.07 & 34.76 & 5.4 & -6.6 & 18.4 \\
\hline 167 & 2.25 & USA & Portland & 45.52 & -122.64 & 37.2 & 35.1 & 87.8 \\
\hline 168 & 2.23 & Poland & Warsaw & 52.26 & 21.02 & -2.4 & -0.4 & 12.9 \\
\hline 169 & 2.23 & China & Wuxi & 31.58 & 120.29 & 14.1 & 25.3 & 12.8 \\
\hline 170 & 2.20 & Brazil & Belem & -1.45 & -48.48 & 21.9 & 20.4 & 16.5 \\
\hline 171 & 2.20 & China & Nanchang & 28.68 & 115.88 & -3.7 & -12.8 & -4.6 \\
\hline 172 & 2.20 & China & Quanzhou & 24.92 & 118.58 & -3.3 & -7.8 & -1.6 \\
\hline 173 & 2.18 & Paraguay & Asunción & -25.27 & -57.67 & -19.5 & 17.6 & -12.5 \\
\hline 174 & 2.18 & India & Bhilai & 21.22 & 81.43 & 11.8 & 17.7 & 20.4 \\
\hline 175 & 2.18 & USA & Cincinnati & 39.14 & -84.50 & -1.6 & -6.1 & 3.2 \\
\hline 176 & 2.18 & Brazil & Goiania & -16.67 & -49.27 & -0.5 & 2.7 & 19.3 \\
\hline 177 & 2.15 & Romania & Bucharest & 44.44 & 26.10 & -19.7 & -10.3 & -11.7 \\
\hline 178 & 2.15 & Yemen & Sanaa & 15.38 & 44.21 & -1.1 & 13.5 & 7.0 \\
\hline 179 & 2.13 & China & Ningbo & 29.87 & 121.55 & 11.5 & 9.0 & 7.7 \\
\hline 180 & 2.10 & China & Nanning & 22.82 & 108.32 & -22.3 & -18.9 & -18.5 \\
\hline 181 & 2.10 & USA & San Antonio & 29.45 & -98.51 & -14.9 & -7.7 & -6.6 \\
\hline
\end{tabular}




\begin{tabular}{ccccccccc} 
Continued & \multicolumn{10}{l}{} \\
\hline 182 & 2.08 & Iran & Isfahan & 32.63 & 51.65 & 2.3 & 8.9 & 3.8 \\
183 & 2.05 & Pakistan & Gujranwala & 32.15 & 74.18 & -4.2 & 2.3 & -0.7 \\
184 & 2.03 & Australia & Brisbane & -27.46 & 153.02 & -19.8 & -8.8 & -14.4 \\
185 & 2.03 & Pakistan & Hyderabad & 25.37 & 68.37 & -16.1 & -3.4 & -10.5 \\
186 & 2.03 & USA & Kansas City & 39.08 & -94.56 & -15.3 & -12.6 & -6.4 \\
187 & 2.03 & Germany & Munich & 48.14 & 11.58 & -14.0 & 0.8 & -5.5 \\
188 & 2.00 & Sweden & Stockholm & 59.33 & 18.05 & -27.1 & -28.3 & -13.1 \\
189 & 2.00 & Austria & Vienna & 48.22 & 16.37 & -19.1 & -20.9 & -11.6 \\
\hline
\end{tabular}

